\title{
\begin{tabular}{l|l} 
Mibraries & DSpace@MIT
\end{tabular}
}

\author{
MIT Open Access Articles
}

Dynamically Reconfigurable, Multifunctional Emulsions with Controllable Structure and Movement

The MIT Faculty has made this article openly available. Please share how this access benefits you. Your story matters.

Citation: Ku, Kang Hee et al. "Dynamically Reconfigurable, Multifunctional Emulsions with Controllable Structure and Movement." Advanced Materials 31, 51 (October 2019): 1905569 (c) 2019 Wiley

As Published: http://dx.doi.org/10.1002/adma.201905569

Publisher: Wiley

Persistent URL: https://hdl.handle.net/1721.1/128132

Version: Author's final manuscript: final author's manuscript post peer review, without publisher's formatting or copy editing

Terms of use: Creative Commons Attribution-Noncommercial-Share Alike 


\title{
WILEY-VCH
}

\section{Dynamically Reconfigurable, Multi-Functional Emulsions with Controllable Structure and Movement}

\author{
Kang Hee Ku, Jie Li, Kosuke Yoshinaga, Timothy M. Swager* \\ Dr. K. H. Ku, Dr. J. Li, K. Yoshinaga, Prof. T. M. Swager \\ Department of Chemistry, Massachusetts Institute of Technology (MIT), Cambridge, MA \\ 02139, USA \\ Dr. K. H. Ku \\ Department of Chemical and Biomolecular Engineering, Korea Advanced Institute of Science \\ and Technology (KAIST), Daejeon 34141, Republic of Korea \\ E-mail: tswager@mit.edu
}

Keywords: Pickering emulsions, shape-reconfigurable emulsions, particle assembly, magnetic emulsions, metal-coated microcapsules

\begin{abstract}
Dynamically reconfigurable oil-in-water (o/w) Pickering emulsions are developed, wherein the assembly of particles (i.e., platinum-on-carbon $(\mathrm{Pt} / \mathrm{C})$ and iron-on-carbon $(\mathrm{Fe} / \mathrm{C})$ particles) can be actively controlled by adjusting interfacial tensions. A balanced adsorption of particles and surfactants at the o/w interface allows for the creation of inhomogeneity of the particle distribution on the emulsion surface. Complex Pickering emulsions with highly controllable and reconfigurable morphologies are produced in a single step by exploiting the temperature-sensitive miscibility of hydrocarbon and fluorocarbon liquids. Dynamic adsorption/desorption of (polymer) surfactants afford both shape and configuration transitions of multiple Pickering emulsions and encapsulated core/shell structured can be transformed into a Janus configuration. Finally, to demonstrate the intrinsic catalytic or magnetic properties of the particles provided by carbon bound Pt and Fe nanoparticles, two different systems are investigated. Specifically, we demonstrate the creation of a bimetallic microcapsule with controlled payload release and precise modulation of translational and rotational motions of magnetic emulsions, suggesting the potential applications for sensing and smart payload delivery.
\end{abstract}




\section{WILEY-VCH}

Particle-stabilized (Pickering) emulsions have desirable properties that are difficult to implement using small molecule surfactants as a result of their intrinsic functionalities and enhanced stability against coalescence. ${ }^{[1]}$ For example, catalytic and magnetic properties, as well as biocompatibility and environmental friendliness of solid particles have led to their use in fields including oil extraction and recovery, ${ }^{[2]}$ biomedicine, ${ }^{[3]}$ food storage, ${ }^{[4]}$ and heterogeneous catalysis. ${ }^{[5]}$ New applications can be made possible when Pickering emulsions can be made to undergo rapid controlled dynamic reconfiguration. In this context, numerous efforts have focused on the development of particles with dynamically controllable stabilizing activities that respond to external stimuli. ${ }^{[6]}$ Although controlling the stabilization and destabilization of emulsions, including reversible phase inversion between oil-in-water $(\mathrm{o} / \mathrm{w})$ and water-in-oil (w/o), has been extensively studied, ${ }^{[7]}$ achieving reliable dynamic control over the shape and configuration of Pickering emulsions is a significant challenge. The major technological hurdle arises from the limited tunability of the amphiphilic nature and packing structure of particles, and the difficulties in implementing multiple components into Pickering emulsions. ${ }^{[8]}$

We have a continuing interest in stimuli-responsive, dynamically reconfigurable complex emulsions, as a result of their programmable optical, rheological, and electrical properties ${ }^{[9]}$ In the pursuit of dynamic emulsion systems, stimuli-responsive surfactants have been developed that afford a rapid and reversible change of configuration in response to $\mathrm{pH}$, temperature, light, and $\mathrm{CO}_{2} \cdot{ }^{[10]}$ In particular, complex colloids can display analyte-, light-, and $\mathrm{pH}$-triggered configurational changes between core/shell double emulsions and Janus emulsions. Recently, these colloids have been produced with uniform compositions by making use of thermally induced mixing of the phases. ${ }^{[11]}$ This approach enables the large-scale production of multiple component emulsions as well as ultrafast reactivity to the surroundings, which are important characteristics for the practical applications. We anticipate that these same 


\section{WILEY-VCH}

methods can be extended to include designed emulsion-stabilizing particles to afford new dynamically configurational properties to Pickering emulsions.

We demonstrate herein a facile and versatile approach to dynamically reconfigurable, multi-functional emulsions by the tailored assembly of particles at the $\mathrm{o} / \mathrm{w}$ interface. Our strategy starts with precisely balancing surface tensions using surfactant molecules and emulsion-stabilizing particles. Dynamic attachment of polymer surfactants to the Pickering emulsions drives the accumulation of particles to one side of emulsion surface. This approach allows the production of complex Pickering emulsions with highly controllable and reconfigurable morphologies, where the geometries can be switched between encapsulated core/shell and Janus configurations. In addition, the use of platinum-on-carbon (Pt/C) or ironon-carbon $(\mathrm{Fe} / \mathrm{C})$ particles impart catalytic and magnetic properties, respectively. We utilize $\mathrm{Pt} / \mathrm{C}$ particles as a catalyst/nucleation site at the oil/water interface to grow a secondary metal shell around the emulsions, thereby providing a scalable route to permeability-controllable microcapsules. Furthermore, Fe/C particles generate ferromagnetic emulsions with controllable translational and rotational motions in response to dynamic magnetic fields. 


\section{WILEY-VCH}

\section{Results and Discussion}

Commercially available metal-functionalized carbon black particles (i.e., platinum-oncarbon $(\mathrm{Pt} / \mathrm{C})$ and iron-on-carbon $(\mathrm{Fe} / \mathrm{C})$ particles) suspended in water can be used to create particle-stabilized emulsions and provide accessibility to a range of surface chemistries, biocompatibility, and high specific surface areas. ${ }^{[12]}$ When bis(nonafluorobutyl) (trifluoromethyl)amine perfluorotributylamine (fluorocarbon FC-40, density $=1.855 \mathrm{~g} / \mathrm{mL}$, viscosity $=2.2 \mathrm{~nm}^{2} / \mathrm{s}$ ) was used as the oil phase, $\mathrm{Pt} / \mathrm{C}$ and Fe/C particles reside preferentially at the FC-40/water interface. ${ }^{[13]}$ The particles are on average $50 \mathrm{~nm}$ in size and have a specific surface area of approximately $100 \mathrm{~m}^{2} / \mathrm{g}$ and X-ray diffraction (XRD) reveals metal (Pt or Fe) crystallite sizes of 2-3 nm (Figure S1). Carbon black particles have previously been used as emulsifiers, but as a result of their inherent hydrophobicity, additional surface chemistry was needed to increase interactions with water. ${ }^{[12,14]}$ In this work, we take advantage of Pt and Fe particles to tune the hydrophilicity of carbon black driven by the hydrophobic bare surface of carbon and hydrophilic Pt and Fe surface, affording consistent o/w emulsions. The details of the particles (with different components and metal contents) used in this study are summarized in Table 1.

Table 1. Characteristics of emulsion-stabilizing particles used in this study.

\begin{tabular}{cc|ccc}
\hline & Particles & $\begin{array}{c}\text { Metal } \\
\text { Content }(\%)\end{array}$ & $\begin{array}{c}\text { Metal Area } \\
(\mathbf{m} / \mathbf{g})\end{array}$ & $\begin{array}{c}\text { XRD } \\
\text { Crystallite } \\
\text { Size (nm) }\end{array}$ \\
\hline Carbon black & Vulcan XC72R & - & - & - \\
\hline $\mathrm{Pt}_{5} / \mathrm{C}$ & $5 \%$ Platinum on Carbon & 5 & 150 & $<2$ \\
\hline $\mathrm{Pt}_{20} / \mathrm{C}$ & 20\% Platinum on Carbon & 20 & 100 & $2-3$ \\
\hline $\mathrm{Pt}_{60} / \mathrm{C}$ & 60\% Platinum on Carbon & 60 & 60 & $4-5$ \\
\hline $\mathrm{Fe}_{20} / \mathrm{C}$ & 20\% Iron on Carbon & 20 & 90 & $1-3$ \\
\hline
\end{tabular}



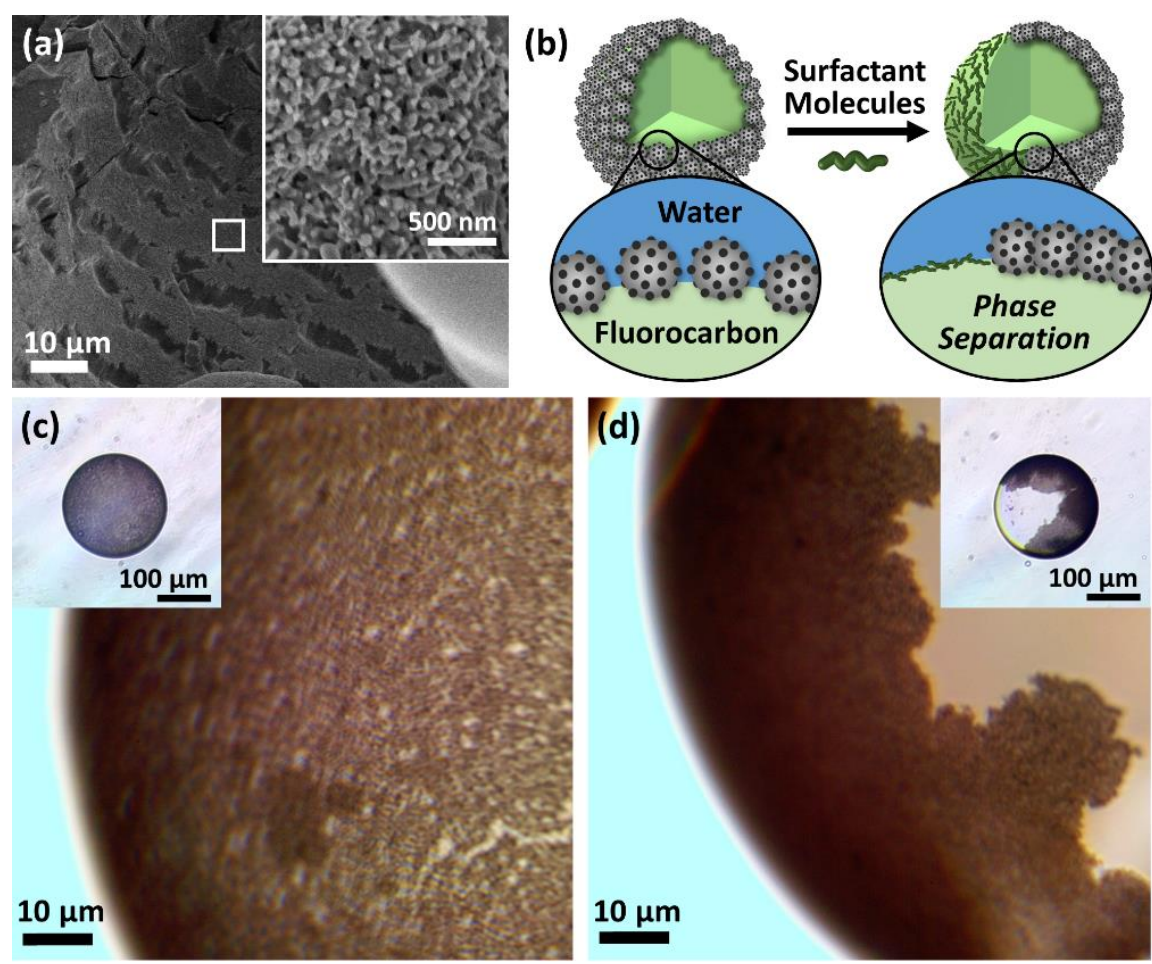

\section{WILEY-VCH}

Figure 1. Dynamic assembly of $\mathrm{Pt} / \mathrm{C}$ particles on the emulsion surface. (a) Cryo-SEM image of FC-40-in-water (FC/W) Pickering emulsion stabilized by $\mathrm{Pt}_{20} / \mathrm{C}$ particles; (b) schematic illustration showing the dynamic assembly of $\mathrm{Pt} / \mathrm{C}$ particles on the surface of Pickering emulsion driven by a balanced attachment of polymer surfactants to the emulsion surface; (cd) bright-field optical microscopic image of an FC/W Pickering emulsion stabilized by $\mathrm{Pt} / \mathrm{C}$ particles (c) before and (d) after adding Zonyl FS-300 (10 mg/mL, 2-3 drops); (e-g) bright-field optical microscopic images of FC/W Pickering emulsions stabilized by $\mathrm{Pt} / \mathrm{C}$ particles after adding three different surfactants: (e) Tween-20, (f) Triton X-100, and (g) SDS.

Pickering emulsions were successfully generated by emulsifying FC-40 into an aqueous solution containing $\mathrm{Pt}_{20} / \mathrm{C}$ particles. The particles uniformly covered the entire surface of the emulsion, and no coalescence was observed after one month. To obtain detailed insight into the structure of the particle aggregates at the oil/water interface, the emulsions were characterized by cryo-scanning electron microscopy (cryo-SEM). Multiple layers of $\mathrm{Pt} / \mathrm{C}$ particles form closely packed aggregates at the interface as revealed in the high magnification image (Figure 1a). Clusters are harder to displace from $\mathrm{o} / \mathrm{w}$ interfaces than individual $\mathrm{Pt} / \mathrm{C}$ particles because the displacement energy scales with the square of the particle size, and hence these assemblies make for very stable emulsions. ${ }^{[1 \mathrm{~g}]}$ When emulsions were formed at a lower concentration of 


\section{WILEY-VCH}

particles, the coverage of the emulsion surface was incomplete, however stable emulsions were still observed. The effect of particle concentration and the $\mathrm{Pt}$ to $\mathrm{C}$ ratio on the emulsion stability (size) is detailed in the Supporting Information Figures S2 and S3, and Table S1.

Considering the high specific surface area of Pt/C particles and nonspecific binding capability of carbon, we needed to establish a model framework for dynamic assembly of particles on the emulsion surface and the role of additional small molecule surfactants. Previous reports observed the coalescence of emulsions ${ }^{[15]}$ or the displacement of particles ${ }^{[14 b, 16]}$ driven by the addition of surfactants that produce dramatic drops in the o/w interfacial tension. We hypothesized that a more balanced addition of surfactants to a Pickering emulsion could reconfigure the particles into specific domains at the emulsion surface. To control the assembly of Pt/C particles on the emulsion surface, 2-3 drops of a $10 \mathrm{mg} / \mathrm{mL}$ solution of Zonyl FS-300 (a non-ionic fluorous surfactant with a linear chemical formula of $\mathrm{F}\left(\mathrm{CF}_{2}\right)_{\times} \mathrm{CH}_{2} \mathrm{CH}_{2} \mathrm{O}\left(\mathrm{CH}_{2} \mathrm{CH}_{2} \mathrm{O}\right)_{y} \mathrm{H}$ ) were added to the Pickering emulsions (Figure 1b) while observing the emulsion with a microscope. Figures 1c and $\mathbf{d}$ show the optical microscopic images of Pickering emulsions before and after adding Zonyl to the emulsion surface. The Pt/C particles have an initial uniform coverage, but rapidly segregate to one side with the addition of Zonyl and create densely jammed Pt/C particles. (See Movie S1 for the real-time movement of $\mathrm{Pt} / \mathrm{C}$ particles on the emulsion surface.) This behavior is attributed to the strong adsorption of both the particles and Zonyl to the interface and induced phase separation. In this case, the fractional change in the interfacial tension between FC-40 and water upon the addition of the Zonyl $\left(\left(\gamma_{F C / W}-\gamma_{F C / W+Z o n y l}\right) / \gamma_{F C / W}\right)$ is comparable with the fraction of the emulsion surface area covered by particles. ${ }^{[14 b]}$ (Details are in the Supporting Information.) Although the time scale is different depending on the surfactant concentration, similar behavior is observed regardless of surfactant concentration above the critical micelle concentration (CMC). The effect of the surfactant concentration on their assembly is summarized in Figure S4. The observed dynamic movement of particles is strongly dependent on the surfactant. We observed 


\section{WILEY-VCH}

three different phenomena: 1) segregation to one side forming densely jammed particles with Tween-20 (Figure 1e), 2) displacement of particles from the emulsion surface by the addition of Triton X-100 (Figure 1f), and 3) continuous movement of rafts of Pt/C particles at the emulsion surface when sodium dodecyl sulfate (SDS) was added (Figure 1g and Movie S2). These differences are explained by the adsorption characteristics of the surfactants at the FC40/water interface. Triton X-100 adsorbs strongly thereby dramatically reducing the interfacial tension between FC-40 and water, and this stabilization is sufficient to displace particles. In contrast, the lower adsorption energy of SDS or CTAB (hexadecyltrimethylammonium bromide) to the interface results in continuous migration of $\mathrm{Pt} / \mathrm{C}$ particles on the emulsion surface instead of phase separation. ${ }^{[17]}$
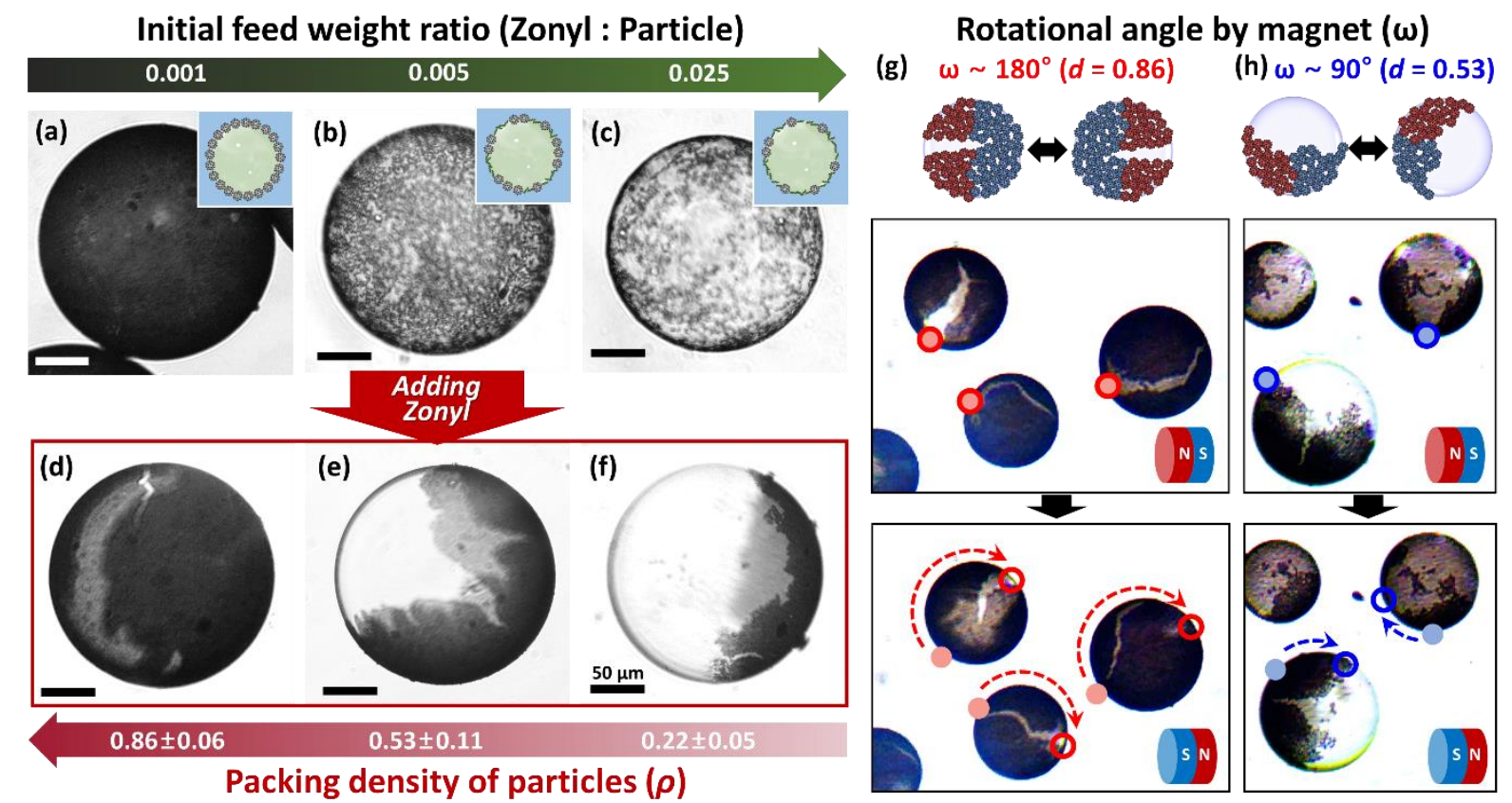

Figure 2. Control of packing density and inhomogeneity of particle distribution on the emulsion surface for tunable translational and rotational emulsion motion. (a-c) Brightfield optical microscopic images of Pickering emulsions stabilized by a mixture of Zonyl and $\mathrm{Fe}_{20} / \mathrm{C}$ particles with different feed weight ratios of Zonyl to particles (a) 0.001, (b) 0.005, and (c) 0.025 ; (d-f) bright-field optical microscopic images of Pickering emulsions after adding concentrated solutions $(10 \mathrm{mg} / \mathrm{mL}$ ) of Zonyl to emulsions in (a) to (c). The packing density of particles $(\rho)$ was measured to be (d) 0.86 , (e) 0.53 , and (f) 0.22 ; (g, h) rotational motion of 


\section{WILEY-VCH}

magnetic emulsions driven by south-north pole inversion of the magnet $((\mathrm{g})$ large rotational angle $\left(\omega \sim 180^{\circ}\right)$ at $\rho=0.86$, and (h) small $\omega\left(\sim 90^{\circ}\right)$ at $\rho=0.53$, respectively).

We were interested to determine the types of structures that spontaneously form if both Zonyl and particles were present during the initial emulsification. To this end, we prepared a series of emulsions stabilized by different feed weight ratios of Zonyl to $\mathrm{Pt} / \mathrm{C}$ or $\mathrm{Fe}_{20} / \mathrm{C}$ particles of $0.001,0.005$, and 0.025 . Only a small amount of Zonyl surfactant is needed to significantly change the packing density (\% coverage) of the particles. As shown in Figures 2a to 2c (Figures S5a to S5c for $\mathrm{Pt} / \mathrm{C}$ particles), the $\mathrm{Fe} / \mathrm{C}$ particles uniformly covered the emulsion surface, but the packing density decreased from $0.86 \pm 0.06$ and $0.53 \pm 0.11$ to $0.22 \pm 0.05$ as the initial ratio of Zonyl to particles increased. In addition, as a result of the decrease of interfacial tension between FC-40 and aqueous surrounding medium, the mean diameter of emulsions decreased from 184 and 173 to $152 \mu \mathrm{m}$, respectively. When an additional concentrated Zonyl solution (10 mg/mL, 2-3 drops) was added to each Pickering emulsion formulation, all of the $\mathrm{Fe} / \mathrm{C}$ particles rapidly reassembled on one side, forming a jamming structure of Fe/C particles, similar to Figure 1d. However, as a result of differences in the initial space between particles the surface area covered by particles was variable (Figures $2 \mathbf{d}$ to $\mathbf{2 f}$ ). The results for Pt/C particles are summarized in Figures S5d to S5f.

Application of a magnetic field ( $~ 500$ Gauss) results in the magnetization of the Fe/C Pickering emulsions (i.e., the south-north (S-N) pole orientation), and this magnetization remains even when the external magnetic field is removed. This feature is attributed to a jammed state of the $\mathrm{Fe} / \mathrm{C}$ particles (i.e., disordered structure with mechanical rigidity) that creates on only few-nanometer spatial separation between adjacent magnetic particles, which allows the formation of a ferromagnetic layer. ${ }^{[18]}$ For example, emulsions in Figure 2(c) (unjammed state, $\rho<0.5$ ) can move toward the magnet, but do now display ferromagnetic properties. This magnetism allows for controllable translational motion (i.e., back-and-forth or 


\section{WILEY-VCH}

continuous one-directional movement) by switching the pole direction of a proximate magnet (Movie S3). In addition, different degrees of rotational angle were observed depending on the packing density of particles $(\rho)$ and the respective magnetic domains (Figures $\mathbf{2 g}-\mathbf{h}$ ). We prepared two sets of magnetic emulsions with different values of $\rho$ and observed their rotational movements under the magnetic field. When the value of $\rho$ was 0.86 , the rotational angle $(\omega)$ of emulsions almost reached to $180^{\circ}$ as shown in Figure $2 \mathrm{~g}$ and in this case the $\mathrm{N}$ and $\mathrm{S}$ domains are roughly symmetrically disposed over the particle. In contrast, smaller $\omega$ 's were observed with lower coverage with $\rho=0.53$ displaying an approximately $90^{\circ}$ rotation in response to an inversion of the applied magnetic field (Figure 2h). These results reveal that sufficient ferromagnetism was created on the surface of emulsion with higher coverage of $\mathrm{Fe} / \mathrm{C}$ particles, allowing translational and rotational motions by an external magnetic field, in a controlled manner. The translational and rotational rolling motions of magnetic Pickering emulsions can be observed in Movies S3 and S4, respectively.
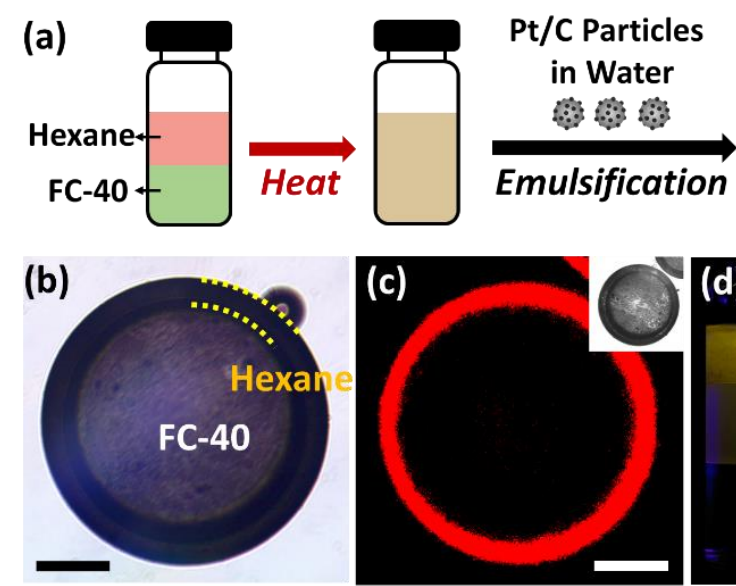
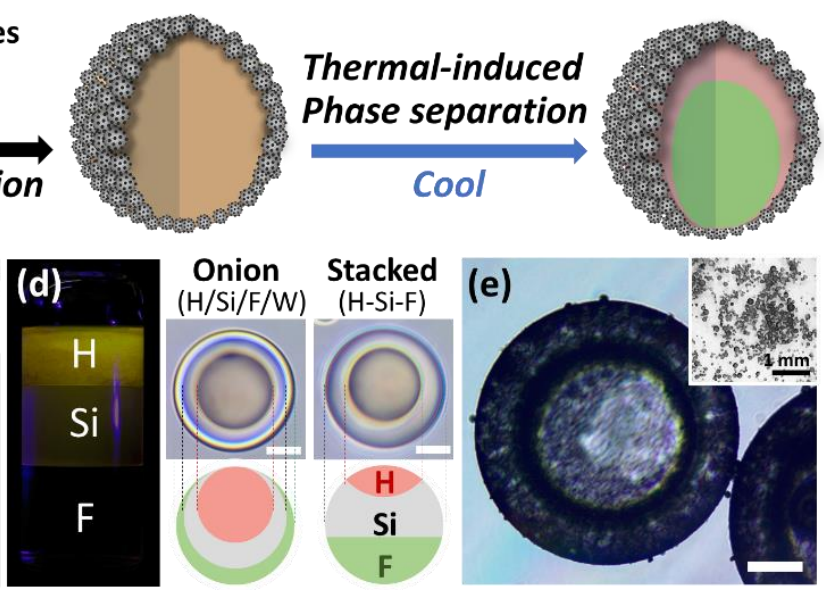

Figure 3. Production of complex Pickering emulsions. (a) Schematic illustration of the creation of a double Pickering emulsion based on temperature-induced phase separation of HC (i.e., hexane) and FC (i.e., FC-40) liquids; (b) bright-field optical microscopic images and (c) lateral confocal cross-section of FC/HC/W double Pickering emulsions (FC-40/hexane/water). HC-soluble perylene dye (red) selectively partitions in the hexane. (d) Phase-separated three different liquids composed of silicon oil $(\mathrm{Si})$, hydrocarbon oil $(\mathrm{H})$, and fluorinated oil $(\mathrm{F})$, and top view of the complex emulsions of triple onion-like structures (stabilized by Zonyl) and Janus configurations with axially stacked liquids (stabilized by the mixture of Zonyl and SDS). 


\section{WILEY-VCH}

(e) Top-view of the bright-field optical microscopic image (inset for low magnification) of complex Pickering emulsions (stabilized by Pt/C particles, Janus configuration with axially stacked H-Si-F liquids). Scale bars are $50 \mu \mathrm{m}$.

To produce a greater diversity of structures and function we endeavored to extend our dynamic Pickering emulsion methods to more complex double and triple emulsions. Fluorocarbon (FC) and hydrocarbon (HC) liquids are often immiscible at room temperature, but most have a low upper critical solution temperature $\left(T_{c}\right)$ and mix with gentle heating. ${ }^{[9 a}$, 9b, 11a, 11b] To explore the feasibility of using a temperature-induced phase separation route to create more complex Pickering emulsions, we emulsified (10 s at $3000 \mathrm{rpm}$ by a vortex) a mixture of hexane and FC-40 with a 1:1 volume ratio above their $T_{c}$ in an aqueous solution containing Pt/C particles. Subsequent cooling below $T_{c}$ induced phase separation and structured core/shell double Pickering emulsions (Figure 3a). Although these emulsions were polydisperse in size, the morphology and the composition of the emulsions were highly uniform. (The effect of particle concentration and the $\mathrm{Pt}$ to $\mathrm{C}$ ratio on the stability of a double emulsion is detailed in the Supporting Information Figures S6 and S7, and Table S2.) Interestingly, there is preferential interaction between $\mathrm{HC}$ and $\mathrm{Pt} / \mathrm{C}$ particles as evidenced by their selective assembly at the hexane/water interface. In the double emulsion this leads to an outer HC phase interfacing with water (Figure 3b). Complex emulsions allow for chemical partitioning of solutes during phase, and $\mathrm{HC}$-soluble perylene dye is used to selectively identify the $\mathrm{HC}$ phase in lateral confocal cross-sectional images of $\mathrm{FC} / \mathrm{HC} / \mathrm{W}$ double Pickering emulsions (Figure 3c). By controlling the feed volume ratio of FC-40 to hexane (i.e, from $2: 1,1: 1$, to $1: 2$ ), the shell thickness can be varied (Figures S8). Pickering emulsions with even higher-order complexity are possible by extending the same principles to a three-phase system. For example, we produced Pickering emulsions comprising silicon oil (methylhydrosiloxane-dimethylsiloxane copolymers (Si)), hydrocarbon oil (a mixture of mineral oil and octadecane $(\mathrm{H})$ ), and 


\section{WILEY-VCH}

fluorinated oil (ethyl nonafluorobutyl ether $(\mathrm{F})$ ) in a volume ratio 1:1:2, such that the liquids mixed when heated and separated into three phases upon cooling. As reported in our previous work, ${ }^{[11 a]}$ the use of Zonyl and SDS allowed generating complex structures such as triple onionlike shape (H/Si/F/W emulsion with Zonyl) or stacked configuration (H-Si-F (from top) with Zonyl and SDS) as shown in Figure 3d. When this three-fluid mixture was emulsified with $\mathrm{Pt} / \mathrm{C}$ particles, a Janus configuration $\mathrm{H}-\mathrm{Si}-\mathrm{F}$ stacked emulsions were generated as a result of the adsorption of Pt/C particles at the interface of water and both $\mathrm{HC}$ and silicone oil (Figure 3e).
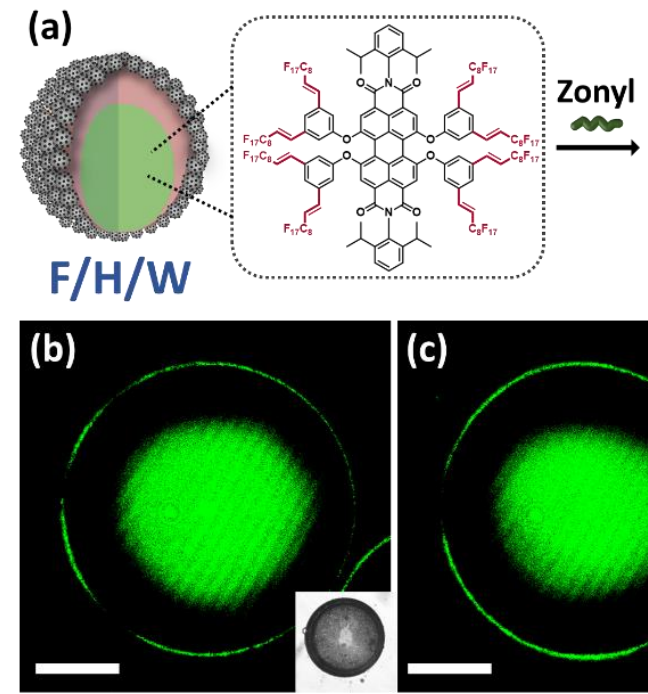
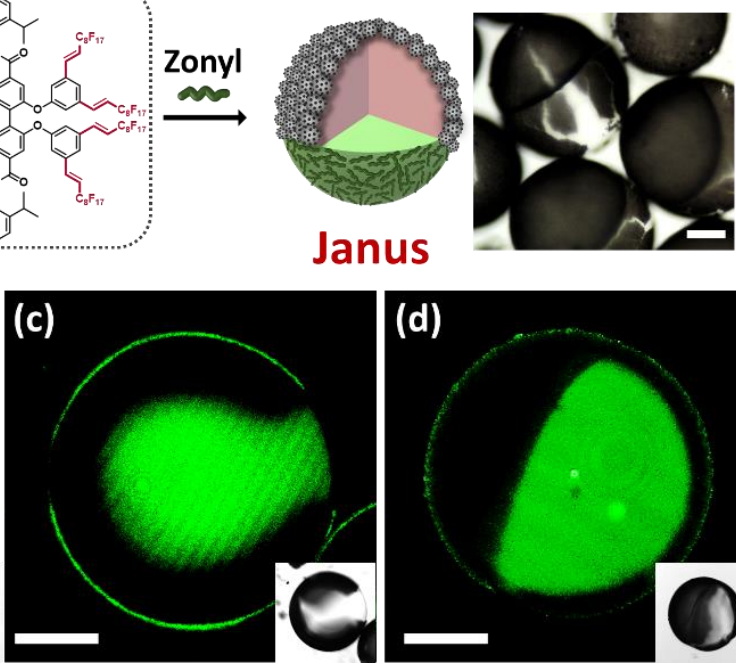

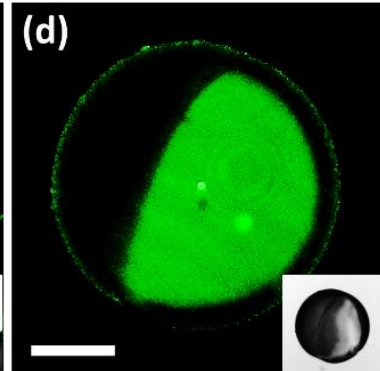

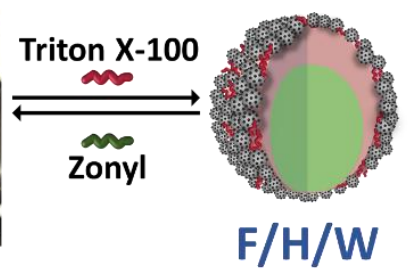

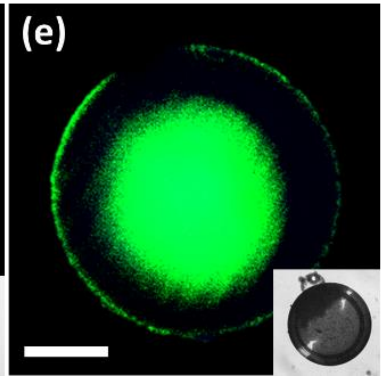

Figure 4. Dynamically reconfigurable double Pickering emulsion. (a) Schematic illustration showing reversible, dynamic reconfiguration of emulsion morphology between core/shell (FC/HC/W) and Janus types driven by adsorption and desorption of Zonyl and Triton X-100 to the surface of double Pickering emulsions; (b-e) lateral confocal cross-section of shapechanging double Pickering emulsions (b) FC/HC/W emulsion stabilized with $\mathrm{Pt} / \mathrm{C}$ particles only, (c, d) Janus emulsion after adding Zonyl to (b), and (e) FC/HC/W emulsion after adding Triton X-100 to (d). Fluorofluorescent perylene bisimide dyes were used to selectively partition into the FC phase. Scale bars are $50 \mu \mathrm{m}$.

The morphology of the complex Pickering emulsion can be controlled by slight changes of the interfacial tensions at $\mathrm{HC}$ /water or $\mathrm{FC} /$ water interface. This change is triggered by the addition of surfactants having a selective preference to the $\mathrm{FC}$ or $\mathrm{HC}$ to the aqueous phase of the Pickering emulsion. Herein, we used Zonyl and Triton X-100, which preferentially interact 


\section{WILEY-VCH}

with FC and HC, respectively (Figure 4a). ${ }^{[1 \mathrm{~b}]}$ We also utilized fluorofluorescent perylene bisimide dyes, which show exclusive solubility in FC-40, ${ }^{[19]}$ for direct imaging of the morphological changes. Using $\mathrm{Pt} / \mathrm{C}$ particles as the sole surfactant resulted in $\mathrm{FC} / \mathrm{HC} / \mathrm{W}$ core/shell emulsions, as a result of the favorable hydrophobic interaction between $\mathrm{Pt} / \mathrm{C}$ particles and hexane (Figure 4b). Addition of a small amount of a concentrated Zonyl solution resulted in a Janus morphology wherein both hexane and FC-40 were exposed to the aqueous surrounding (Figures $\mathbf{4 c}$ to $\mathbf{4 d}$ ). The real-time movie for the shape reconfiguration of Pickering emulsion from core/shell to Janus is provided in Movie S5. Subsequent addition of Triton X100 to the Janus emulsions changes the morphology back to an $\mathrm{FC} / \mathrm{HC} / \mathrm{W}$ core/shell, and the strong adsorption of Triton X-100 results in dissociation of the Zonyl surfactants (Figure 4e). We note that during the latter morphological transition, the particles remain strongly attached to the hexane/water interface indicating high interfacial adsorption energy for the $\mathrm{Pt} / \mathrm{C}$ particles. The morphological transition between Janus and core/shell was reproducible with changing surfactant concentrations in the continuous aqueous phase over 10 cycles. 


\section{WILEY-VCH}
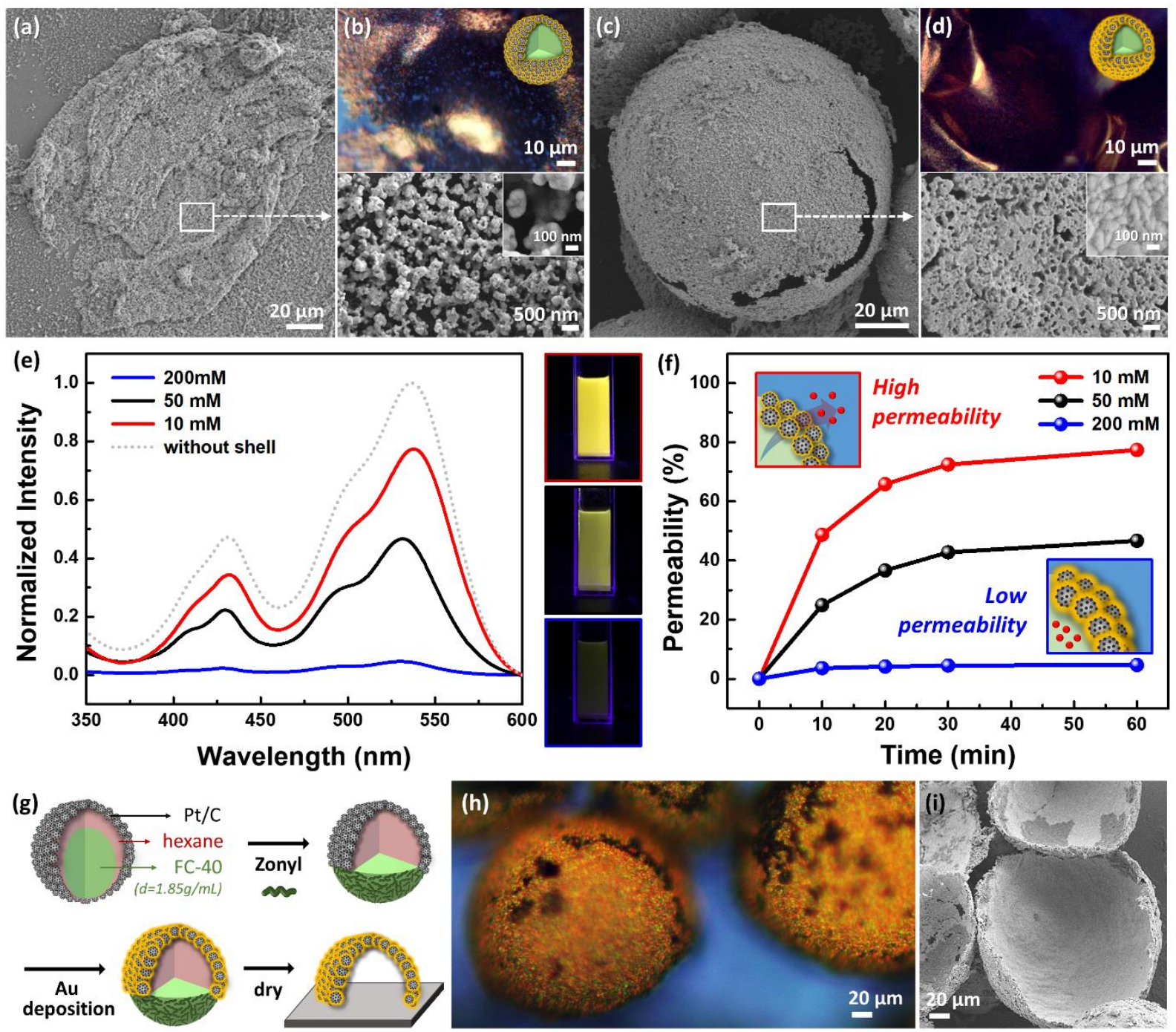

Figure 5. Use of emulsion-stabilizing particles as catalysts for the fabrication of shapetunable bimetallic microcapsule. (a, c) SEM and (b, d) optical microscope images of goldcoated $\mathrm{Pt} / \mathrm{C}$ microcapsules prepared with $10 \mathrm{mM}(\mathrm{a}, \mathrm{b})$ and $200 \mathrm{mM}(\mathrm{c}, \mathrm{d})$ concentrations of $\mathrm{HAuCl}_{4}$; (e) UV-vis absorbance spectra and fluorescence photographs of FC suspensions of gold-coated microcapsules containing dye molecules (FC-soluble payloads) wherein release of the $\mathrm{FC}$ soluble dye was monitored after $1 \mathrm{~h}$ from microcapsules with $\mathrm{HAuCl}_{4}$ concentrations of $10 \mathrm{mM}$ (red), $50 \mathrm{mM}$ (black), and $200 \mathrm{mM}$ (blue). The absorbance intensities were normalized based on the case where all dye molecules were released from the emulsion (grey dot line). (f) Time-dependent dye permeability through gold microcapsules; (g) synthetic route to create a $\mathrm{Pt} / \mathrm{Au}$ bimetallic hemispherical shell using Janus Pickering emulsions through an electroless deposition process; (h) optical microscope image of hemispherical shells tilted at an angle of $45^{\circ}$; and (i) SEM images of upside-down hemispherical shells.

To demonstrate the utility of our dynamic Pickering emulsions, $\mathrm{Pt} / \mathrm{C}$ particles were used as catalysts for electroless gold plating to produce shape-tunable bimetallic microcapsules. $\mathrm{Pt} / \mathrm{C}$ 


\section{WILEY-VCH}

particles nucleate the growth of gold according to the following reaction: $2 \mathrm{HAuCl}_{4}+3 \mathrm{H}_{2} \mathrm{O}_{2}$

$\stackrel{\mathrm{Pt}}{\rightarrow} 2 \mathrm{Au}+3 \mathrm{O}_{2}+8 \mathrm{HCl}^{[20]}$ It is worth noting here that localization of the $\mathrm{Pt} / \mathrm{C}$ particles to the emulsion surface drastically limits the precipitation of solid metal in the continuous phase.

We prepared a series of gold-coated microcapsules from a Pt/C-stabilized emulsion template with varying gold concentrations from 10 to $200 \mathrm{mM}$. Figures 5a to 5d show optical reflective light micrographs and SEM images of the resulting bimetallic microcapsules. The successful growth of the gold on the emulsion surface is verified from the EDX graph in Figure S9. As expected, a much denser and thicker shell was fabricated at higher gold concentrations. For example, the microcapsule produced at $10 \mathrm{mM}$ of gold salt collapsed after drying (Figure 5a), while a stable hollow microcapsule is produced at $200 \mathrm{mM}$, which persists after removing the FC and water (Figure 5c). The controllable thickness and the porosity of the gold-coated microcapsules were further explored by dye permeability through the microcapsules. A concentrated solution of FC-40 containing $0.5 \mathrm{wt} \%$ of fluorofluorescent perylene bisimide dye (FC-soluble payload) was emulsified in water by $\mathrm{Pt} / \mathrm{C}$ particles followed by the gold deposition. The emulsions were then isolated and re-dispersed in FC solvent to induce the release of dye molecules from the core into the bulk. The time-release of dye molecules was monitored by UV-vis absorbance spectra and observed by fluorescence imaging of FC suspensions of microcapsules (Figures 5e and S10). The dye permeabilities were calculated by the normalized intensity at $535 \mathrm{~nm}$ relative to the signal from complete release of the dye and are summarized in Figure 5f. Rapid loss of core dyes (up to $80 \%$ ) was observed with the thinner gold shell, while more than $90 \%$ of the dye was retained after $1 \mathrm{hr}$ in the case of the microcapsules produced with $200 \mathrm{mM} \mathrm{HAuCl}_{4}$. The gold deposition was also carried out using Janus Pickering emulsions (Figure 5g). The hemispherical shell shape is confirmed by the optical microscope image tilted at an angle of $45^{\circ}$ (Figure 5h) and upside-down SEM image (Figure 5i). We note that the Janus emulsions and hence the $\mathrm{Pt} / \mathrm{C}$ particles align with the curved surface pointing 
upward on surfaces as a result of the lower density of hexane $(0.655 \mathrm{~g} / \mathrm{mL})$ as compared to FC40 liquids $(1.855 \mathrm{~g} / \mathrm{mL})$. Therefore, after gold deposition and solvent evaporation, hemispherical gold shells are all aligned as shown in Figure $\mathbf{5 h}$ on the glass substrate.

To summarize, we report a powerful platform to produce dynamically reconfigurable functional Pickering emulsions through controlled assembly of active particles. A balanced adsorption of small molecule surfactants (Zonyl) at the surfaces of Pt/C- and Fe/C-stabilized emulsions created inhomogeneous particle distributions on the emulsion surfaces. Importantly, single-step fabrication of complex Pickering emulsions with highly controllable and reconfigurable morphologies (i.e., between Janus and core/shell) was achieved by exploiting the temperature-sensitive miscibility of silicon, organic, and fluorocarbon oils. We further demonstrated the production of bimetallic microcapsules with tunable permeability and the magnetization with associated directed movement of emulsions. The dynamic and controlled localization of particles described herein enables the preparation of multi-functional Pickering emulsions with reconfigurable shapes, and anticipates new opportunities in sensing, smart coating, and drug delivery. 


\section{WILEY-VCH}

\section{Experimental Section}

Materials: The following chemicals were used as received: platinum-on-carbon $(\mathrm{Pt} / \mathrm{C}$, $5 \%, 20 \%$, and $60 \%$ ), iron-on-Vulcan (Fe/C, $20 \%$ ), Vulcan XC 72R (purchased from Fuel Cell Store), bis(nonafluorobutyl)(trifluoromethyl)amine perfluorotributylamine (fluorocarbon FC-40), ethyl nonafluorobutyl ether (purchased from SynQuest), 50-55\% methylhydrosiloxane-dimethylsiloxane copolymers (purchased from Gelest), octadecane (99\%), mineral oil (light), Zonyl FS-300 (Zonyl, 40\% solids), sodium dodecyl sulfate (SDS, 99\%) Triton X-100, cetyltrimethylammonium bromide (CTAB), Tween-20, perylene, gold(III) chloride hydrate $\left(\mathrm{HAuCl}_{4},>99 \%\right)$, hydrogen peroxide $\left(\mathrm{H}_{2} \mathrm{O}_{2}, 35 \%\right)$ (purchased from SigmaAldrich), and hexane (98\%) (purchased from Alfa Aesar). Fluorofluorescent perylene bisimides were synthesized according to previous literature. ${ }^{[19]}$

General procedure to produce particle-stabilized FC-in-water emulsions: To prepare the aqueous surfactant solution, $\mathrm{Pt} / \mathrm{C}$ or $\mathrm{Fe} / \mathrm{C}$ particles were dispersed in $2.0 \mathrm{~mL}$ of water $(1$ $\mathrm{mg} / \mathrm{mL}$ ). Then, $0.5 \mathrm{~mL}$ of FC (i.e., FC-40) was vortex emulsified in the aqueous surfactant solution for $30 \mathrm{~s}$ at $3,000 \mathrm{rpm}$. To control the packing density of particles on the emulsion surface, a mixture of Zonyl and $\mathrm{Pt} / \mathrm{C}$ (or Fe/C) particles was used as an aqueous surfactant solution, where the initial feed weight ratios of the Zonyl to particles were varied in a range from 0.001 to 0.025 . Dynamic assembly of particles on the emulsion surface was explored by adding 2-3 drops of concentrated Zonyl solutions (or Triton X-100, Tween 20, SDS, and CTAB, $10 \mathrm{mg} / \mathrm{mL}$ ) into the Pickering emulsions.

Fabrication of shape-changing double Pickering emulsions: Hexane and FC-40 were combined in equal volumes and heated to above the suspension's $T_{c}$ to allow the two liquids to form a homogeneous mixture. An aqueous solution containing Pt/C particles ( $10 \mathrm{~mL}, 1 \mathrm{mg} / \mathrm{mL})$ heated above $T_{c}$ was then added, and the resulting mixture was quickly shaken using a vortex at 3,000 rpm within $10 \mathrm{~s}$. The emulsions were then cooled to induce phase separation. To 


\section{WILEY-VCH}

demonstrate shape-changing double Pickering emulsions, 2-3 drops of Zonyl or Triton X-100 solutions $(10 \mathrm{mg} / \mathrm{mL})$ were added to the emulsions.

Gold deposition on the emulsion surface via electroless plating: An aqueous solution containing $\mathrm{HAuCl}_{4}$ and $\mathrm{H}_{2} \mathrm{O}_{2}$ was added to the dispersion of $\mathrm{Pt} / \mathrm{C}$-stabilized emulsions to initiate the electroless deposition process, ${ }^{[20 \mathrm{c}]}$ and the reaction was kept for $20 \mathrm{~min}$. To control the thickness of the bimetallic shell, the concentration of gold salt was varied from 10 to 200 $\mathrm{mM}$. To explore the dye permeability through the gold-coated microcapsule, a concentrated solution of FC-40 (0.3 mL) containing $0.5 \mathrm{wt} \%$ of fluorofluorescent perylene bisimide dye was emulsified in water by $\mathrm{Pt} / \mathrm{C}$ particles $(2 \mathrm{~mL}, 1 \mathrm{mg} / \mathrm{mL})$, and these emulsions were used for gold deposition. After the removal of excess water, the emulsions were re-dispersed in FC to induce the release of dye molecules from the core of the emulsion to the surroundings (Figure S8a). The real-time release of dye molecules was monitored by UV-vis absorption measurement, and the dye permeability was calculated by the normalized intensity at $535 \mathrm{~nm}$ based on the case where all dye molecules were released from the emulsion.

Characterization: Bright-field optical images were taken with a Zeiss Axiovert 200 inverted microscope equipped with a Zeiss AxioCam HRc camera. The confocal images were obtained using a Zeiss LSM 700 laser scanning confocal microscope at the Whitehead Institute. To characterize Pt/C particles and bimetallic shell structures, SEM (Merlin and Crossbeam 540 Zeiss) and transmission electron microscope (TEM, FEI-Tecnai) were used. During the fracturing of the cryo-SEM sample, the frozen oil was removed, allowing direct visualization of the particles residing at the interface. 


\section{WILEY-VCH}

\section{Supporting Information}

Supporting Information is available from the Wiley Online Library or from the author.

\section{Acknowledgments}

This research was supported by a Vannevar Bush Faculty Fellowship (Grant \# N000141812878) and the National Research Foundation Grant (2018R1D1A1B07040671 and 2016R1E1A1A02921128) from the Korean Government. Also, we thank the Koch Institute Swanson Biotechnology Center for technical support, specifically Nanotechnology Materials Core. K.Y. thanks Funai Overseas Scholarship for financial support.

\section{Conflict of Interest}

The authors declare no conflict of interest.

Received: ((will be filled in by the editorial staff))

Revised: ((will be filled in by the editorial staff)) Published online: ((will be filled in by the editorial staff)) 


\section{WILEY-VCH}

\section{References}

[1] a) R. Aveyard, B. P. Binks, J. H. Clint, Adv. Colloid Interface Sci. 2003, 100-102, 503; b) J.-W. Kim, D. Lee, H. C. Shum, D. A. Weitz, Adv. Mater. 2008, 20, 3239; c) J. Wu, G. H. Ma, Small 2016, 12, 4633; d) H. Katepalli, V. T. John, A. Tripathi, A. Bose, J. Colloid Interface Sci. 2017, 485, 11; e) N. P. Ashby, B. P. Binks, Phys. Chem. Chem. Phys. 2000, 2, 5640; f) P. Wei, Q. Luo, K. J. Edgehouse, C. M. Hemmingsen, B. J. Rodier, E. B. Pentzer, ACS Appl. Mater. Interf. 2018, 10, 21765; g) B. P. Binks, S. O. Lumsdon, Langmuir 2001, 17, 4540; h) K. H. Ku, H. Yang, S. G. Jang, J. Bang, B. J. Kim, J. Polym. Sci., Part A: Polym. Chem. 2016, 54, 228.

[2] a) A. P. Sullivan, P. K. Kilpatrick, Indust. Eng. Chem. Res. 2002, 41, 3389; b) D. Lee, D. A. Weitz, Adv. Mater. 2008, 20, 3498; c) X. Wang, Y. Shi, R. W. Graff, D. Lee, H. Gao, Polymer 2015, 72, 361; d) Y. Chen, Y. Bai, S. Chen, J. Ju, Y. Li, T. Wang, Q. Wang, ACS Appl. Mater. Interf. 2014, 6, 13334.

[3] a) S.-H. Hu, B.-J. Liao, C.-S. Chiang, P.-J. Chen, I. W. Chen, S.-Y. Chen, Adv. Mater. 2012, 24, 3627; b) S.-H. Hu, R.-H. Fang, Y.-W. Chen, B.-J. Liao, I.-W. Chen, S.-Y. Chen, Adv. Funct. Mater. 2014, 24, 4144; c) J. Frelichowska, M.-A. Bolzinger, J. Pelletier, J.-P. Valour, Y. Chevalier, Int. J. Pharm. 2009, 371, 56.

[4] E. Dickinson, Curr. Opin. Colloid Interface Sci. 2010, 15, 40.

[5] a) Z. Chen, C. Zhao, E. Ju, H. Ji, J. Ren, B. P. Binks, X. Qu, Adv. Mater. 2016, 28, 1682; b) M. Pera-Titus, L. Leclercq, J. M. Clacens, F. De Campo, V. Nardello-Rataj, Angew. Chem. Int. Ed. 2015, 54, 2006.

[6] a) J. T. Tang, P. J. Quinlan, K. C. Tam, Soft Matter 2015, 11, 3512; b) B. P. Binks, R. Murakami, S. P. Armes, S. Fujii, Angew. Chem. Int. Ed. 2005, 44, 4795; c) H. Q. Yang, T. Zhou, W. J. Zhang, Angew. Chem. Int. Ed. 2013, 52, 7455.

[7] a) F. Tu, D. Lee, J. Am. Chem. Soc. 2014, 136, 9999; b) C. Liang, Q. Liu, Z. Xu, ACS Appl. Mater. Interf. 2014, 6, 6898; c) K. H. Ku, Y. J. Lee, G.-R. Yi, S. G. Jang, B. V. K. J. Schmidt, K. Liao, D. Klinger, C. J. Hawker, B. J. Kim, Macromolecules 2017, 50, 9276; d) Q. Lan, C. Liu, F. Yang, S. Liu, J. Xu, D. Sun, J. Colloid Interface Sci. 2007, 310,260 .

[8] a) P. Dommersnes, Z. Rozynek, A. Mikkelsen, R. Castberg, K. Kjerstad, K. Hersvik, J. Otto Fossum, Nat. Commun. 2013, 4, 2066; b) C. Miesch, I. Kosif, E. Lee, J.-K. Kim, T. P. Russell, R. C. Hayward, T. Emrick, Angew. Chem. Int. Ed. 2012, 51, 145; c) I. Kosif, M. Cui, T. P. Russell, T. Emrick, Angew. Chem. Int. Ed. 2013, 52, 6620; d) Z. G. Cui, L. L. Yang, Y. Z. Cui, B. P. Binks, Langmuir 2010, 26, 4717.

[9] a) C.-J. Lin, L. Zeininger, S. Savagatrup, T. M. Swager, J. Am. Chem. Soc. 2019, 141, 3802; b) S. Nagelberg, L. D. Zarzar, N. Nicolas, K. Subramanian, J. A. Kalow, V. Sresht, D. Blankschtein, G. Barbastathis, M. Kreysing, T. M. Swager, M. Kolle, Nat. Commun. 2017, 8, 14673; c) J. Bae, T. P. Russell, R. C. Hayward, Angew. Chem. Int. Ed. 2014, 53, 8240; d) K. H. Ku, J. M. Shin, D. Klinger, S. G. Jang, R. C. Hayward, C. J. Hawker, B. J. Kim, ACS Nano 2016, 10, 5243; e) L. Ge, W. Tong, Q. Bian, D. Wei, R. Guo, J. Colloid Interface Sci. 2019, 554, 210; f) L. Ge, J. Li, S. Zhong, Y. Sun, S. E. Friberg, R. Guo, Soft Matt. 2017, 13, 1012.

[10] a) P. Brown, C. P. Butts, J. Eastoe, Soft Matt. 2013, 9, 2365; b) L. Besnard, F. Marchal, J. F. Paredes, J. Daillant, N. Pantoustier, P. Perrin, P. Guenoun, Adv. Mater. 2013, 25, 2844. 


\section{WILEY-VCH}

[11] a) L. D. Zarzar, V. Sresht, E. M. Sletten, J. A. Kalow, D. Blankschtein, T. M. Swager, Nature 2015, 518, 520; b) Y. He, S. Savagatrup, L. D. Zarzar, T. M. Swager, ACS Appl. Mater. Interf. 2017, 9, 7804; c) L. Ge, S. E. Friberg, R. Guo, Curr. Opin. Colloid Interface Sci. 2016, 25, 58.

[12] A. Saha, A. Nikova, P. Venkataraman, V. T. John, A. Bose, ACS Appl. Mater. Interf. 2013, 5, 3094.

[13] E. Santini, F. Ravera, M. Ferrari, M. Alfè, A. Ciajolo, L. Liggieri, Colloid Surf., A 2010, 365,189

[14] a) K. C. Powell, A. Chauhan, Langmuir 2014, 30, 12287; b) H. Katepalli, V. T. John, A. Bose, Langmuir 2013, 29, 6790; c) B. Rodier, A. de Leon, C. Hemmingsen, E. Pentzer, ACS Macro Lett. 2017, 6, 1201.

[15] B. P. Binks, A. Desforges, D. G. Duff, Langmuir 2007, 23, 1098.

[16] a) C. Vashisth, C. P. Whitby, D. Fornasiero, J. Ralston, J. Colloid Interface Sci. 2010, 349, 537; b) C. P. Whitby, D. Fornasiero, J. Ralston, J. Colloid Interface Sci. 2009, 329 , 173.

[17] C.-H. Chang, E. I. Franses, Colloid Surf., A 1995, 100, 1.

[18] a) X. Liu, N. Kent, A. Ceballos, R. Streubel, Y. Jiang, Y. Chai, P. Y. Kim, J. Forth, F. Hellman, S. Shi, D. Wang, B. A. Helms, P. D. Ashby, P. Fischer, T. P. Russell, Science 2019, 365, 264; b) A.-H. Lu, E. L. Salabas, F. Schüth, Angew. Chem. Int. Ed. 2007, 46, 1222; c) B. D. Korth, P. Keng, I. Shim, S. E. Bowles, C. Tang, T. Kowalewski, K. W. Nebesny, J. Pyun, J. Am. Chem. Soc. 2006, 128, 6562; d) S. Melle, M. Lask, G. G. Fuller, Langmuir 2005, 21, 2158.

[19] K. Yoshinaga, T. M. Swager, Synlett. 2018, 29, 2509.

[20] a) A. L. Tasker, S. Puttick, J. Hitchcock, O. J. Cayre, I. Blakey, A. K. Whittaker, S. Biggs, J. Mater. Chem. B 2018, 6, 2151; b) J. P. Hitchcock, A. L. Tasker, E. A. Baxter, S. Biggs, O. J. Cayre, ACS Appl. Mater. Interf. 2015, 7, 14808; c) K. Stark, J. P. Hitchcock, A. Fiaz, A. L. White, E. A. Baxter, S. Biggs, J. R. McLaughlan, S. Freear, O. J. Cayre, ACS Appl. Mater. Interf. 2019, 11, 12272. 


\section{WILEY-VCH}

Dynamically reconfigurable, multi-functional emulsions are developed through the controlled assembly of active particles. Dynamic attachment of polymer surfactants to the emulsions afford both shape and configuration transitions of complex Pickering emulsions between encapsulated core/shell and Janus configurations. Finally, the production of bimetallic microcapsules with controlled payload release and the magnetization with the associated directed movement of emulsions are demonstrated.

Keyword Pickering emulsions, shape-reconfigurable emulsions, particle assembly, magnetic emulsions, metal-coated microcapsules

K. H. Ku, J. Li, K. Yoshinaga, T. M. Swager*

\section{Dynamically Reconfigurable, Multi-Functional Emulsions with Controllable Structure and Movement}

ToC figure

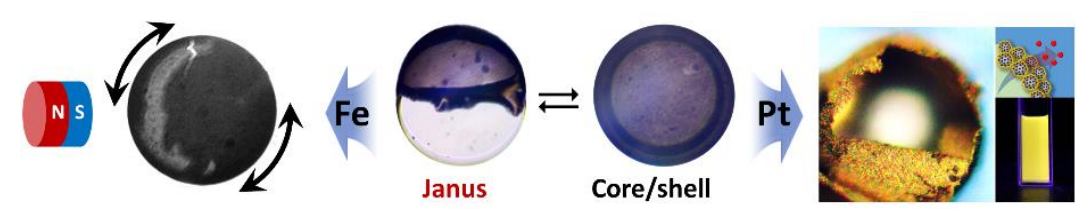




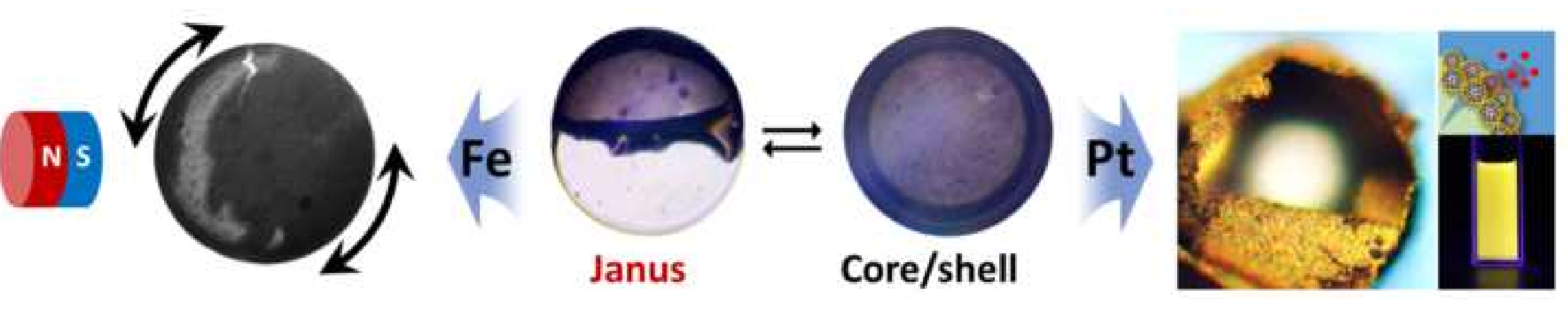


Click here to access/download Supporting Information Pickering_KangheeKu_Revised SI_20191004_highlight.pdf 
Click here to access/download Supporting Information Pickering_KangheeKu_Revised Manuscript_20191004_highlight.pdf 
Click here to access/download Supporting Information Movie S1_Zonyl.mp4 
Click here to access/download Supporting Information Movie S2_Others.mp4 
Click here to access/download Supporting Information Movie S3_Translational Movement.mp4 
Click here to access/download Supporting Information Movie S4_Rotational Movement.mp4 


\section{Click here to access/download
Supporting Information
Movie S5_Janus.mp4 \\ Slick here to access/download
Movie S5_Janus.mp4 Click here to access/download
Supporting Information
Movie S5_Janus.mp4}


Click here to access/download Supporting Information Pickering_KangheeKu_Revised SI_20191004_clean.pdf 
Figure 4

.

Figure 4

\section{Click here to access/download \\ Production Data Figure4.tif Production Data

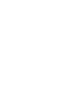

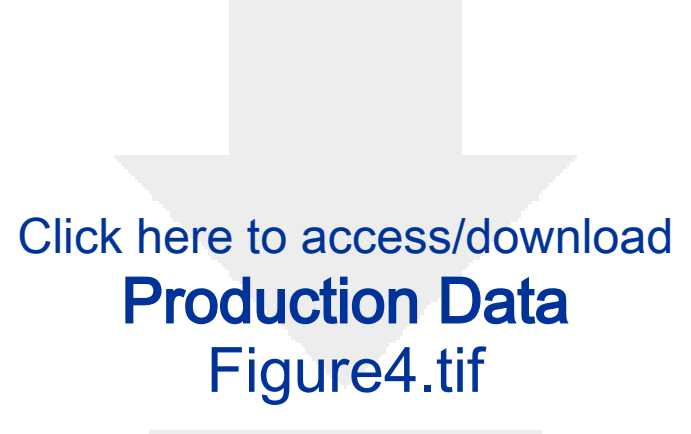

Figure - 
Click here to access/download

Plick here to access/downlo
Production Data
Figure5.tif

Plick here to access/do
Production Data
Figure5.tif

Figure 5

\section{Production Data

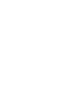

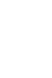

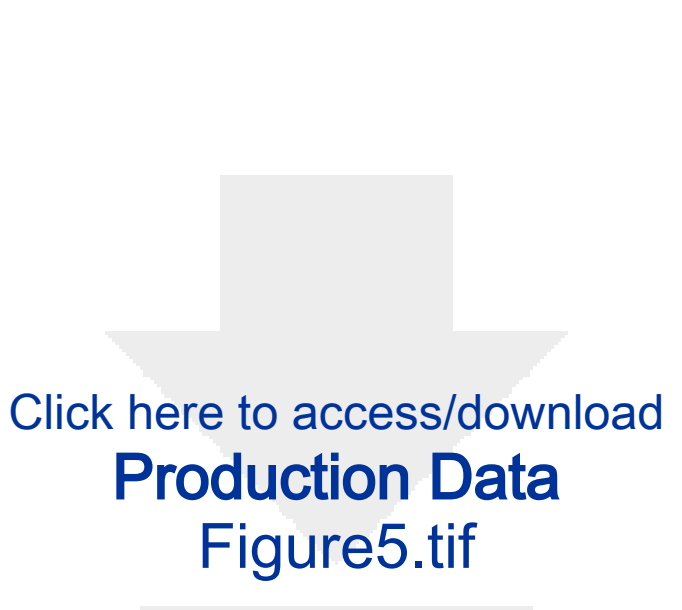

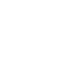

.

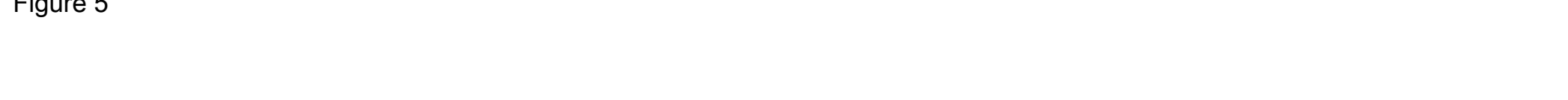

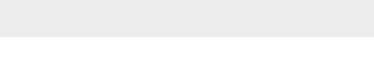

7

trang (a)

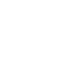
(1)

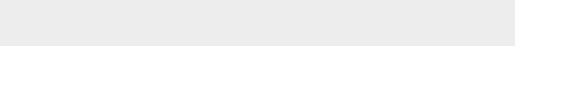


Figure 2

Click here to access/download Production Data

Figure2.tif

Figure Figure2.tif

.

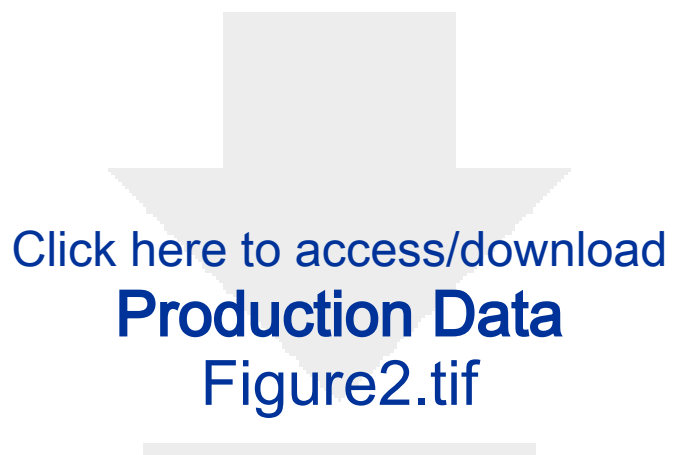


Figure 1

Click here to access/download

Production Data

Figure1.tif

\section{a}

.

(a)

